\title{
To using predicate/transition nets as instrument of inference in expert systems
}

\author{
Prof.Dipl.-Ing H. Koerner Dr.-Ing. V. Franz \\ Dipl.-Ing. P. Boettcher \\ University of Kassel/Germany - Department of Civil Engineering
}

\section{Summary}

PrT-Nets are usefull as an instrument of inference. The article will give a short introduction in the PrT-Net theory and shows on same example how to transfer the work process in a PrT-Net structure.

\section{Introduction}

Processes are changes of state in systems. For planning and controlling by using of expertsystems they have to be represented in it with their structures, their relations and their behaviour. The logical relation of the real system concerning all relevant exogenous, and mostly stochastical conditions have to be found in the model.

An expert system needs an inference instrument connecting user, real system and data base management system. This inference instrument has to settle following conditions:

- to represent the real structures and relations

- to represent the behaviour of the real system

- to use by computer

- to connect the elements of the expert system

Predicate/Transition-Nets developed by Petri [1] (therefore often named Petri-Nets) and other $[7.8]$ are suitable for this purpose [1:3]. 
To using PrT-Nets as instrument of inference in expert systems

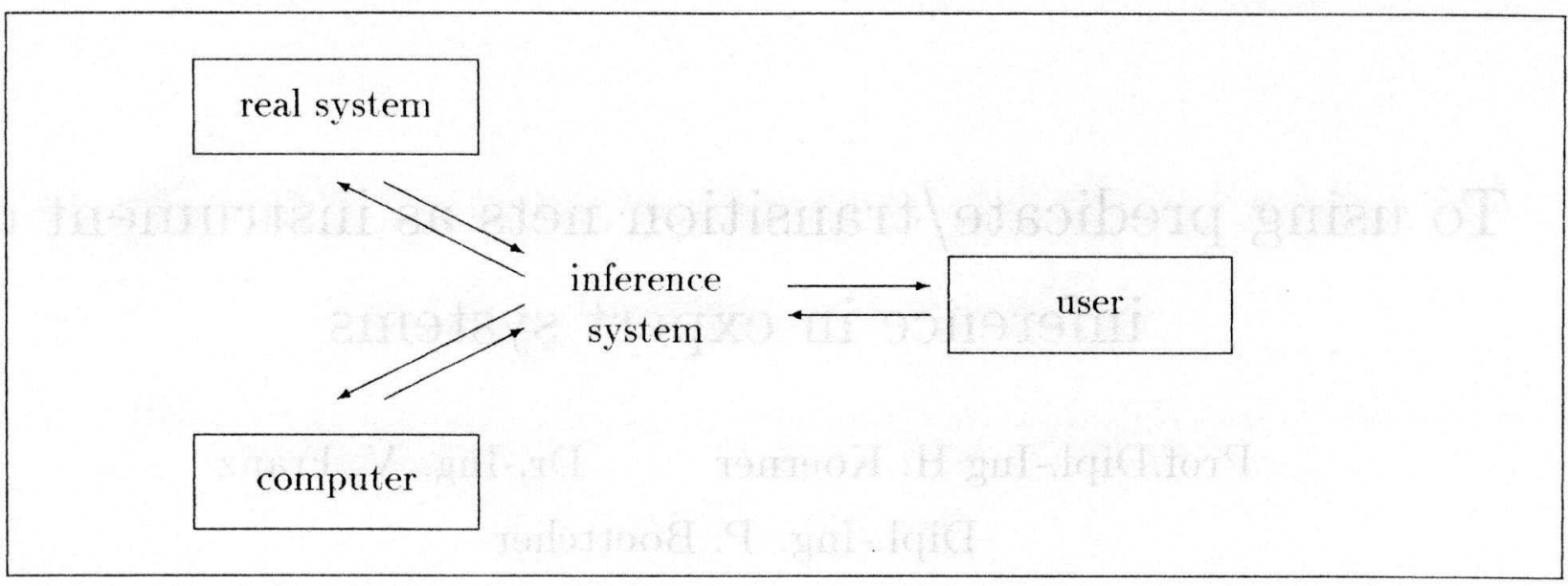

Figure 1: connection between real system, user and computer

\section{Predicate/Transition-Nets}

Elements of all kinds of system structurs are represented by four symbols

$T \square=$ boxes, event, transition

$P \bigcirc=$ circles, place, predicate

$F \quad \longrightarrow=$ arrows

The net is defined by a tripel $(P, T, F)$

$P \cap T=\oslash \mathrm{P}$ and $\mathrm{T}$ are disjunction sets

$P \perp T=F \quad \mathrm{P}$ and $\mathrm{T}$ are combined by $\mathrm{F}$

$F \quad=\oslash$ there exists no empty net

$F \subseteq P \times T \cup T \times P$ succesion exists only between $\mathrm{P}$ and $\mathrm{T}$, never between $\mathrm{P}$ and $\mathrm{P}$ or $\mathrm{T}$ and $\mathrm{T}$

A predicate/transition-net consists of following constituents:

1. a directed net $(\mathrm{P}, \mathrm{T}, \mathrm{F})$ where

- $\mathrm{P}$ is the set of predicates (relations between n-tuples of individual subjects)

- $\mathrm{T}$ is the set of transitions (events, actions)

- $F \subseteq P \times T \cup T \times P$ is the set of arcs 
To using PrT-Nets as instrument of inference in expert systems

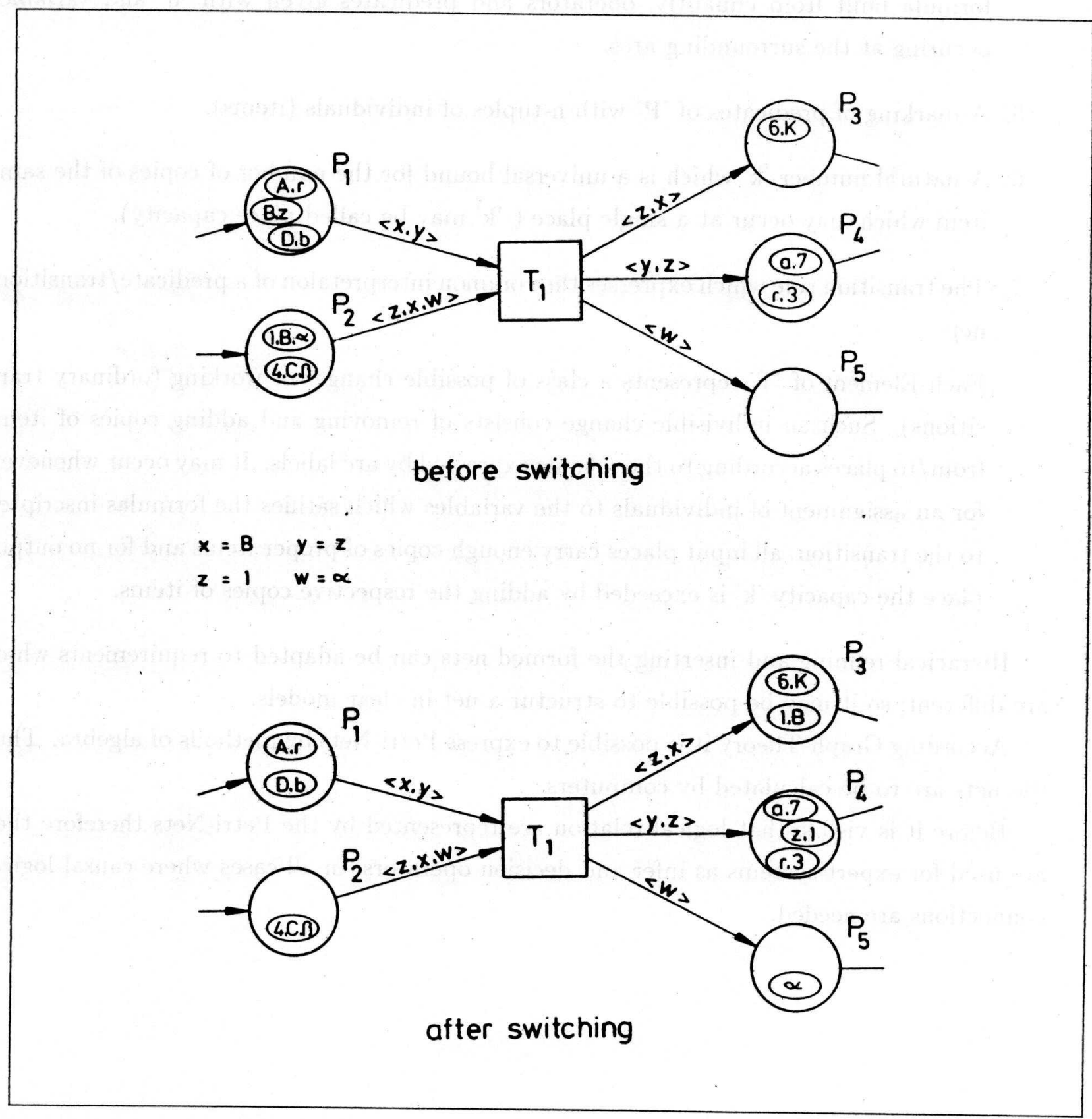

Figure 2: Switching in a Prt-Net 
To using PrT-Nets as instrument of inference in expert systems

3. A labelling of arcs assigning to all elements of ' $F$ ' a formal sum of $n$-tuples of variables where ' $n$ ' is the 'arity' of the predicate concepted on the arc

4. An inscription on transition assigning to some elements of ' $T$ ' a quantitfier-free logical formula built from equalitiy, operators and predicates given with ' $u$ ' and variables occuring at the surrounding arcs.

5. A marking of predicates of 'P' with n-tuples of individuals (items).

6. A natural number ' $k$ ' which is a universal bound for the number of copies of the same item which may occur at a single place ( ' $k$ ' may be called place capacity).

7. The transition rule which expresses the common interpretaion of a predicate/transitionnet:

Each Element of ' $\mathrm{T}$ ' represents a class of possible changes of working (ordinary transitions). Such an indivisible change consists of removing and adding copies of items from/to places according to the scheme expressed by arc labels. It may occur whenever, for an assignment of individuals to the variables which satifies the formulas inscripted to the transition. all input places carry enough copies of proper items and for no output place the capacity ' $k$ ' is exceeded by adding the respective copies of items.

Hieracical refining and inserting the formed nets can be adapted to requirements which are different; so it may be possible to structur a net in clear models.

According Graph-Theory it is possible to express Petri-Nets by methods of algebra. Thus the nets are to be calculated by computers.

Before it is visible that logical relation are represented by the Petri-Nets therefore they are used for expert-systems as infer and decision operators, in all cases where causal-logical connections are needed. 
To using PrT-Nets as instrument of inference in expert systems

\section{Example of Using the PrT-Nets}

Following figure 3 show the use of PrT-Nets in civil engineering:

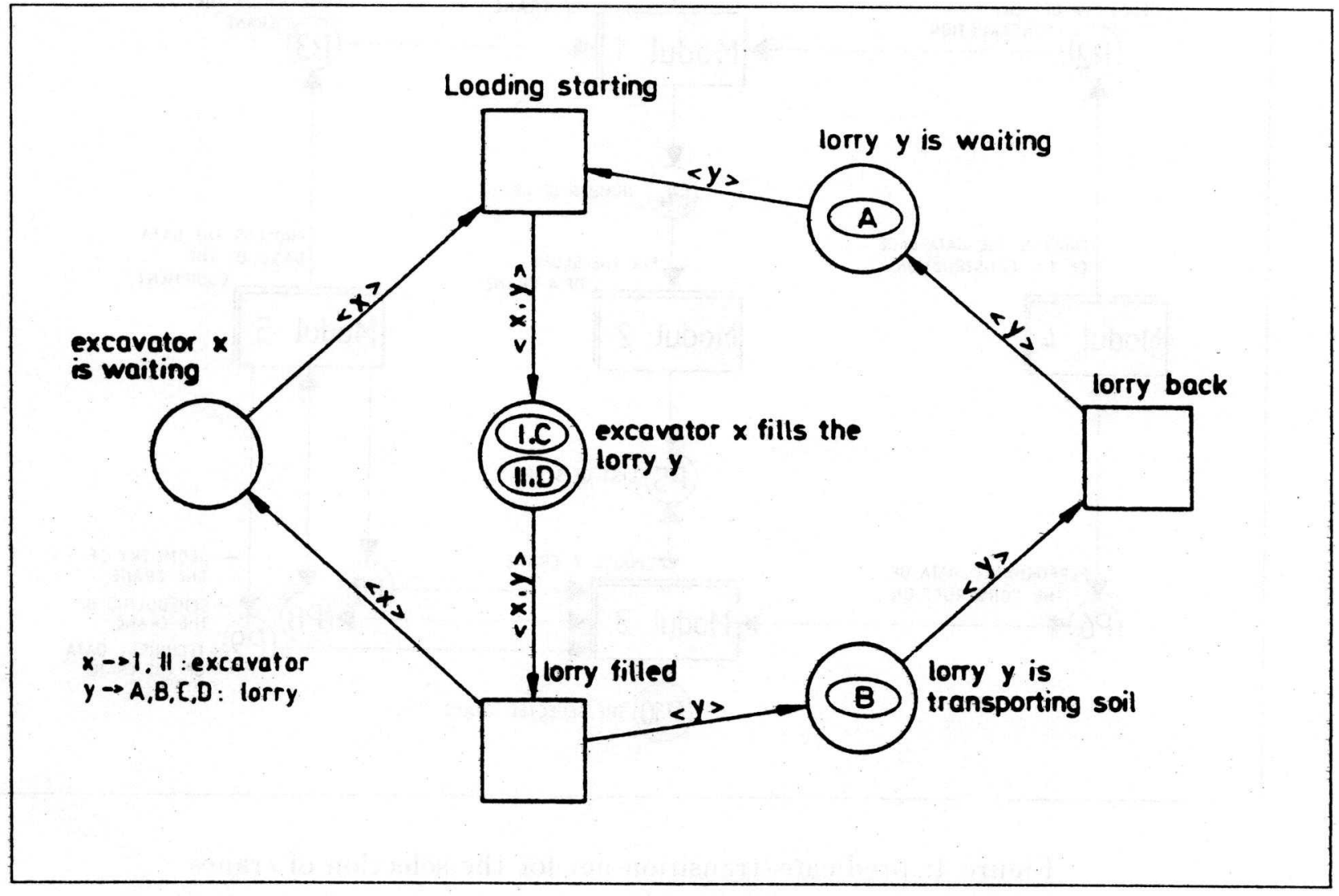

Figure 3: Example: quarry. 2 excavators, 4 lorries

\section{Selection of cranes}

The working method for judging and selecting of a crane is very complex. It is divided into three kinds of tasks:

- determine the number of crane for the site,

- fix the scope of the crane and

- choose a crane.

The correlation between the tasks can be shown by a Prt-Net (see figure 4). Each task will be an event of the PrT-Net and is pictured as a modul (Modul 1 to 3). In the background 
To using PrT-Nets as instrument of inference in expert systems

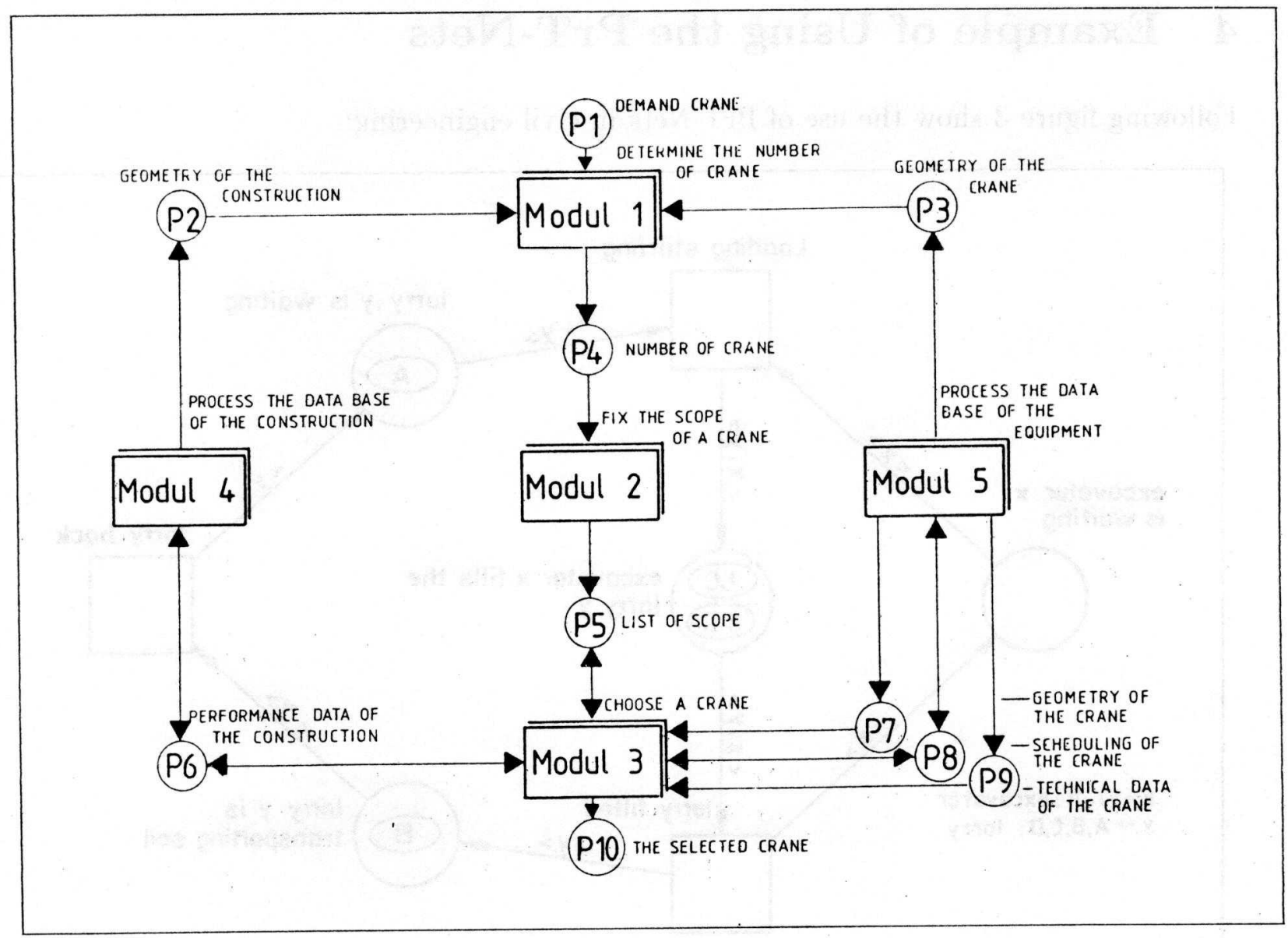

Figure 4: predicate/transition net for the selection of cranes

of each modul there are several levels, in which the operating steps of a task are described in detail.

For the selection of a crane information is needed about the building and the equipment. This information is described in the places $\mathrm{P} 1$ to $\mathrm{P} 10$. The treatment of the information will be done by a data bank management system. The data bank management system is defined as an event of the net, because the system will save and modify the information. In the PrT-Net the data base of the building and the equipment is separated in two moduls (modul 4 and 5 ) in order to get a better overall view .

\subsection{Choose a crane}

As an exemple for the different moduls of the net, modul 3 'choose a crane' should be analyzed. The figure 5 shows the next level of the modul 3 as a PrT-Net.

The operating steps of the task can be realized as a event (transition). The information and the decision made before will be write into an item (object with quality) and presented 
To using PrT-Nets as instrument of inference in expert systems

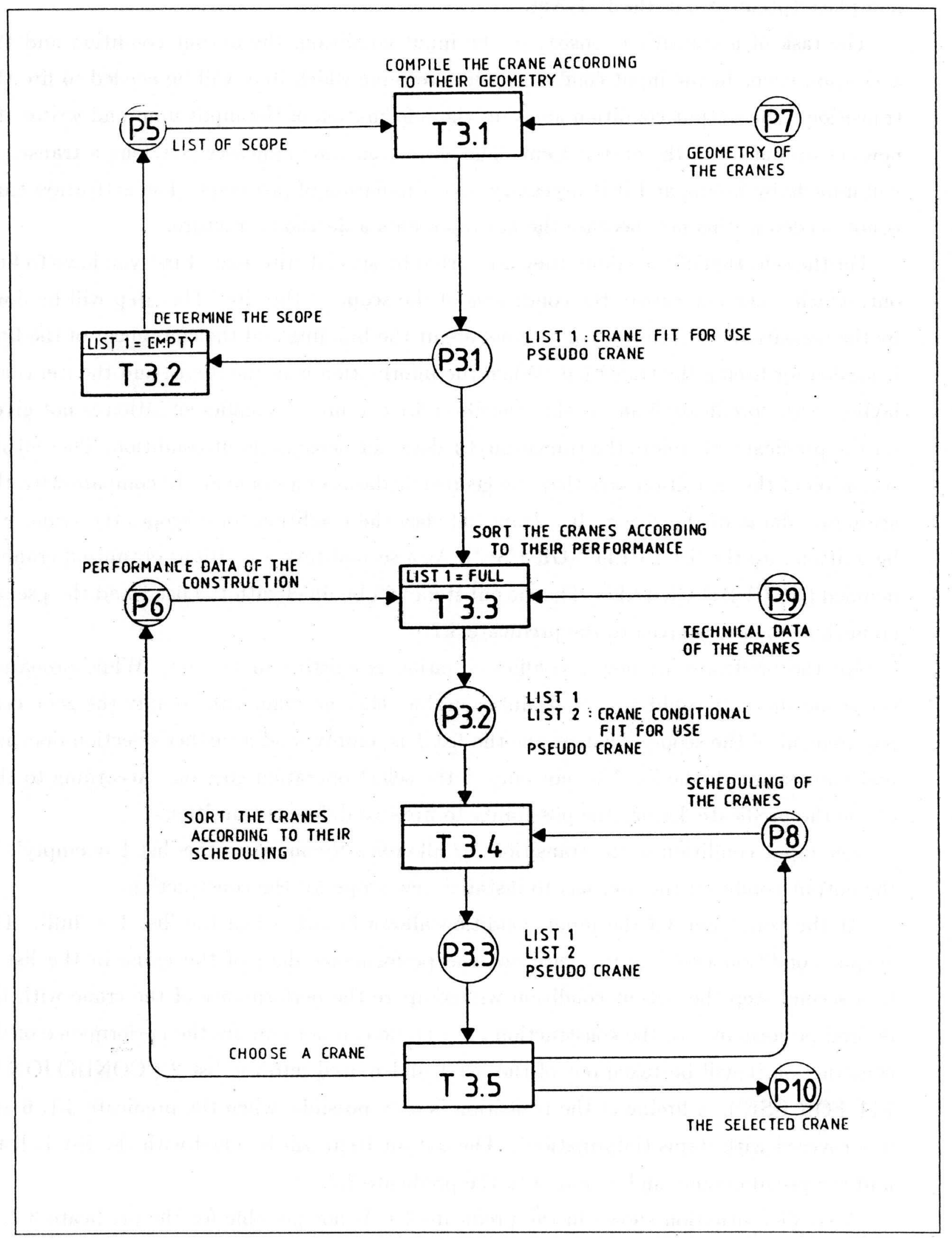

Figure 5: predicate/transition net of the modul 3 'choose a crane' 
To using PrT-Nets as instrument of inference in expert systems

in a place (predicate) of the PrT-Net.

The task of a transition consists of the input condition, the output condition and the activation time. In the input condition you determine which item will be needed to fire the transition. The output condition analyzes the information of the input item und writes the new set up data into the output item. The activation time indicates how long a transition will impede by fireing and it is necessary by a simulation of processes. The activation time is not needed in this net, because the net represents a decision structure.

For the selection of the cranes they are sorted by special criterions. First you have to find out, which crane can satisfy the conditions of the scope of the site. This step will be done by the transition 3.1. Information (items) about the building and the equipment of the firm is needed for fireing the transition. When the information is in the items, and the items are laying on the predicate 5 and 7 , the transition 3.1 can fire. A conflict situation is not given for the predicate, therefore the transition 3.1 does not need an input condition. The output condition of the transition says that the geometric datas of a crane are to compare with the geometric datas of the scope. If a crane satisfies the conditions of a scope, the crane will be written into the list 1 ('FIT FOR USE'). As a second task a fictitious optimized crane is definied ('PSEUDO CRANE'). The output item will be filled with the list 1 and the pseudo crane, and then it is given to the predicate 3.1 .

For the predicate 3.1 now a conflict situation is existing in the net. While preparing the scope the user could elect it so unfavourable, that no crane can comply the geometric requirement of the scope. That means the list 1 is 'empty' and a further selection does not make any sense. If the list 1 is 'not empty' the select operation goes on. According to this choise the predicate 3.1 has the possibility to fire two different transitions.

The input condition of the transition 3.2 allowes a fireing when the 'list $1=$ empty'. In the output condition the user has to install a new scope for the construction.

At the transition 3.3 the input condition allows fireing, when the 'list $1=$ full'. The output condition first has to figure out the performance data of the crane in the list 1. In a second step the output condition will compare the performance of the crane with the desired performance of the construction. If a crane can not comply the performance of the construction it will be taken out of the list 1 and moved into the list 2 ('CONDITIONAL FIT FOR USE'). A fireing of the transition is only possible, when the predicate $3.1,6$ and 9 is covered with items (information). The output item will be filled with the list 1 , list 2 and the pseudo crane, and is moved to the predicate 3.2 .

A conflict situation shown in the predicate 3.1. is not possible for the predicate 3.2. If the list 1 is empty. then no crane can satisfy the requested conditions for performance of the 
To using PrT-Nets as instrument of inference in expert systems

\begin{tabular}{|c|c|c|c|c|c|}
\hline crane typ & $\begin{array}{c}\text { performance } \\
m^{3} / h\end{array}$ & $\begin{array}{c}\text { height } \\
\text { m }\end{array}$ & $\begin{array}{c}\text { distance } \\
\mathbf{m}\end{array}$ & $\begin{array}{l}1991 \\
\ldots \text { A M J J A S O N D }\end{array}$ & $\begin{array}{l}1992 \\
\text { J F M A M J J A S O N D }\end{array}$ \\
\hline ideal crane & 80 & 10 & 40 & ......BBBBBBBBBBBBB & 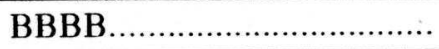 \\
\hline TDK 501 & 100 & 50 & 50 & . ВBВBВBВBВBВBВBB & B \\
\hline TDK 302 & 80 & 20 & 40 & ……... & BВBВВВВВВВ \\
\hline TDK 410 & 50 & 30 & 30 & В & ……… \\
\hline
\end{tabular}

Table 1: example of crane choosing list for the transition 3.5

user always can state which performance date he can use.

As soon as the predicate 3.2 and predicate 8 is covered with an item the transition 3.4 can fire. In the output condition the scheduling of the different cranes will be registered in the lists. The lists, corrected that way, will be written to the output item, and it is given to the predicate 3.3 .

At the last working step, in transition 3.5, the lists will be revised like table 1 showes. Now the user can choose between the different alternativs. Is a crane selected, the data base of the equipment has to be redone with the up date scheduling and the data base of the construction has to be corrected with the actual performance. The output item with this information will be sent to the predicate 6 and 8 . In the predicate 10 the selected crane will be prepared for further use.

\subsection{Recapitulation}

For the judgement and selection of equipment and working methods for a construction you can use serveral methods. The construction has to be estimated and described by code numbers. This activity will be done by people, because the single constructions are to different. For the judgement of performance data and working chains special methods of computation or simulation (see [13]) are usefull. The variety of a working method will be progressed by comparative appreciation.

The PrT-Net make it possible to represent each of the three methods and to combine them. If a certain working process can be described with the assistance of the transitions and predicates, it also can be processed by a computer, with the help of a software like NET for PSI Berlin or POSES for GPC Chemnitz.

\section{References}

[1] Petri, C.A. : Kommunikation mit Automaten. Schriften des Rheinisch-Westfaelischen 
To using PrT-Nets as instrument of inference in expert systems

[2] Petri, C.A. : concepts of net theory, Mathematical foundation of Cumputer Science. Mathematical Institute of Slovak Academic of Science 1973

[3] Petri,C.A.: General Net Theory, Conference on Petri Nets and Related Methods MIT, Cambridge, Mass.,July 1-3, 1975 Proceedings to appear

[4] Petri, C.A. : Interpretation of net theory, Gesellschaft fuer Mathematik und Datenverarbeitung, St. Augustin, Interner Bericht ISF-75-07 1975

[5] Petri, C.A. : eneral net theory; in B Shaw, Ed. Computing System Design Proc. Joint IBM University of Newcastle upon Tyne Seminar: September 1976. University of Newcastle upon Tyne 1977

[6] Petri, C.A. : Introduction to general net theory, in W.Brauer Ed. Net Theory and Application Springer, Berlin 1980

[7] Genrich, H.J./Lautenbach : The analysis of distributed systems by mean of of predicate/transition nets in. G. Kahn, Ed. Semantics and Concurrent Computation, Lecture notes in Computer Science 70 S. 123-146 Springer, Berlin 1979

[8] Genrich, H.J./Lautenbach, K. : System modelling with High-Level Petri-Nets, Theoretical Computer Science Vol. 13 pp 109-136 North-Holland, Publishing Company

[9] Gesellschaft fuer Prozessteuerungs- und Informationssysteme; NET, Version 1.5, Introduction to the NET tool system; Berlin 1985

[10] Grube, U.: Einfuehrung in NET, PSI, Berlin 1985

[11] Koerner H.: Projektplanung und Steuerung mit Petri-Netzen; Projekt Forum, Kassel 1988; Hrsg.: GPM internet, München 1988

[12] Koerner, H./ Franz, V.: Planung und Steuerung von Bauprozessen mit Petri-Netzen; Baumaschine und Technik 5/90 S.207-256; Bauverlag: Wiesbaden 1990

[13] Franz, V.: Planung und Steuerung komplexer Bauprozeese mit modifizierten PetriNetzen; Dissertation GH Kassel 1989 